\title{
Apolipoprotein (a) concentrations and susceptibility to coronary artery disease in patients with peripheral vascular disease
}

\author{
P Groves, A Rees, A Bishop, R Morgan, M Ruttley, N Lewis, I Lane, R Hall
}

\begin{abstract}
Objective-To investigate the relation between apolipoprotein(a) concentrations and angiographically defined coronary artery disease in patients with atheromatous peripheral vascular disease.

Design-40 consecutive patients were recruited at the time of admission for peripheral vascular surgery. All underwent clinical assessment and coronary arteriography. Apolipoprotein(a) concentrations were measured by an immunoradiometric assay.

Setting-Tertiary referral centre.

Subjects-Patients requiring surgical intervention for large vessel peripheral vascular disease.
\end{abstract}

Main outcome measures-Presence or absence and severity and distribution of angiographically defined coronary artery disease. Measurement of circulating contrations of apolipoprotein(a) and other lipid indices.

Results-Coronary artery disease was absent in 11 patients (group 1), mild to moderate in 12 (group 2), and severe in 17 (group 3). The distribution of peripheral vascular disease and of standard lipid indices was similar in these three groups of patients. There was a significant difference in apolipoprotein(a) concentrations between the three groups, with concentrations progressively increasing with the severity of coronary artery disease (mean (95\% confidence interval): group 1, $112 \mathrm{U} / 1$ (52 to 242); group 2, $214 \mathrm{U} / 1$ (129 to 355); group 3, $537 \mathrm{U} / 1$ (271 to 1064) (analysis of variance $p<0.005$ ). The prevalence of coronary artery disease was increased 7.4 fold in patients with apolipoprotein(a) concentrations that were greater than the cohort median (206 $\mathrm{U} / 1)(\mathrm{p}<0.01)$.

Conclusions-The results show an association between apolipoprotein(a) concentrations and angiographically defined coronary artery disease in patients with large vessel peripheral vascular disease. The findings imply differences in the pathogenesis of coronary and peripheral atheroma and suggest that the measurement of apolipoprotein(a) may prove a useful additional tool in the risk factor assessment of patients undergoing peripheral vascular surgery.

(Br Heart J 1993;69:26-30)
There is a high prevalence of coronary artery disease among patients with peripheral vascular disease, which reflects the diffuse nature $\propto$ of atheroma. ${ }^{1}$ Patients with intermittent क claudication are up to four times more likely $\overrightarrow{0}$ than controls to have coronary artery disease $\mathrm{e}^{23}$ and approximately half the deaths that com- $\vec{\sigma}$ plicate peripheral vascular surgery are due to acute myocardial infarction. ${ }^{4}$ While the widespread nature of atheroma implied a common pathogenesis throughout the circulation, the absence of angiographically significant coron-? ary artery disease in more than $30 \%$ of patients with advanced peripheral vascular disease ${ }^{56} \vec{c}$ suggested that this may not be the case. Indeed, differences have emerged from epidemiological g studies regarding the relative risk factors that ${ }^{<}$ are important in the development of coronary $\vec{\oplus}$ and peripheral artery disease, ${ }^{7}$ and the factors 9 that determine the distribution of atheroma throughout the circulation remain poorly understood.

Apolipoprotein(a) (apo (a)) is a modified $\stackrel{2}{\circ}$ glycoprotein that is bound by disulphide bonds $\mathscr{Q}$ to low density lipoprotein to form the $\overrightarrow{\vec{O}}$ lipoprotein(a) $(\mathrm{Lp}(\mathrm{a}))$ complex. $^{8}$ Circulating 3 concentrations of apo(a), and therefore $L p(a)$, are largely genetically determined ${ }^{9}$ and though the function of this lipoprotein remains poorly $\vec{\nabla}$ understood considerable interest has centred around the likelihood that concentrations of $\mathrm{Lp}$ (a) may explain a substantial part of the association between genetic predisposition and $\delta$ coronary risk. ${ }^{10}$ Prospective analysis has identified high concentrations of $\mathrm{Lp}(\mathrm{a})$ as an independent risk factor for subsequent $I$ myocardial infarction or death from coronary heart disease. ${ }^{11}$ Several case-control and ${ }^{\circ}$ angiographic studies have also shown an $N$ association between increased concentrations 0 of $\mathrm{Lp}(\mathrm{a})$ and the presence of coronary artery disease $^{12-14}$ and cerebrovascular disease. ${ }^{15-17} \sum^{2}$ Such an association, however, has not been sought in the presence of advanced atheroma on elsewhere and in this study we investigated the relation between apo(a) concentrations and 0 angiographically defined coronary artery disease in patients with advanced peripheral vascular disease.

Patients and methods

We studied 40 consecutive patients admitted for peripheral vascular surgery. Informed consent was obtained from each patient and the study was approved by the hospital ethics committee. All patients underwent clinical assessment with particular attention paid to the presence or absence of clinical features 
indicative of underlying coronary artery disease. Current medication was reviewed and the presence of risk factors for coronary and peripheral vascular disease was documented. Venous blood was sampled for liver function tests in view of the recognised influence that hepatic disease may exert on circulating concentrations of apo(a). ${ }^{18}$ All patients had the following investigations.

CORONARY AND PERIPHERAL ARTERIOGRAPHY

Coronary arteriography was performed via the right brachial or femoral approach. The angiograms were reported by an experienced cardiac radiologist (MR) who was unaware of the results of the other investigations. A Brandt scoring system ${ }^{19}$ was used which was modified to include an assessment of the coronary circulation supplying both right and left ventricles. This scoring system gives an index of the severity and distribution of coronary artery disease by providing a total myocardial score that depends on the number, degree, and site of coronary stenoses. With this method a minimum score of zero denotes the absence of angiographically demonstrable coronary disease. On the basis of the total myocardial score, patients were divided into three groups: those with absent $(0)$, mild to moderate $(0-9)$, or severe $(>9)$ coronary artery disease.

The distribution of peripheral vascular disease was assessed by arterial or venous catheterisation with conventional or digital subtraction angiography. The pattern of disease was defined anatomically according to the presence or absence of aneurysmal dilatation of the descending aorta or significant $(>50 \%)$ narrowing within the iliac, femoral, or popliteal vessels, or both.

\section{LIPID, LIPOPROTEIN, AND APOLIPOPROTEIN ANALYSIS}

Venous blood was taken after a 12 hour overnight fast. The sample was allowed to coagulate and the serum was separated within six hours and divided into smaller volumes for future lipid and lipoprotein analysis. These samples were stored at $-20^{\circ} \mathrm{C}$ except for those that were later assayed for HDL cholesterol, which were stored at $-70^{\circ} \mathrm{C}$. Total cholesterol and triglyceride were measured by standard enzymatic procedures. ${ }^{2021}$ HDL cholesterol was measured after phosphotungstate/magnesium precipitation ${ }^{22}$ and LDL cholesterol was calculated by the Friedewald formula. ${ }^{23}$ Apolipoprotein A1 and apolipoprotein B were

Table 1 Clinical characteristics of the three groups of patients

\begin{tabular}{lcccc}
\hline & $\begin{array}{c}\text { Group 1 } \\
(n=11)\end{array}$ & $\begin{array}{c}\text { Group 2 } \\
(n=12)\end{array}$ & $\begin{array}{c}\text { Group 3 } \\
(n=17)\end{array}$ & $p$ \\
\hline Age (yr) (mean (SEM)) & $58 \cdot 1(3 \cdot 8)$ & $65 \cdot 0(2 \cdot 5)$ & $64 \cdot 9(1 \cdot 7)$ & NS \\
Sex (M:F) & $8: 3$ & $9: 3$ & $14: 3$ & NS \\
Angina (n(\%)) & $0(0)$ & $4(25)$ & $5(29)$ & NS \\
Hypertensive (n(\%)) & $1(9)$ & $6(50)$ & $8(47)$ & NS \\
Smoker (n(\%)) & $9(82)$ & $10(83)$ & $16(94)$ & NS \\
Family history of CAD (n(\%)) & $3(27)$ & $1(8)$ & $1(6)$ & NS \\
Previous MI (n (\%)) & $0(0)$ & $5(42)$ & $4(23)$ & NS \\
Alcohol intake (n (\%)) & $18(4)$ & $22(10)$ & $22(10)$ & \\
$\quad$ (units/week) (mean (SEM)) & & & & \\
\hline
\end{tabular}

Group 1, no coronary artery disease (CAD); group 2, mild to moderate CAD; group 3, severe CAD. MI, myocardial infarction. measured by a Beckman Immunochemistry analyser. After reduction and hydrolysis of the apo(a) peptide from the $\mathrm{Lp}$ (a) particle, apo(a) concentrations were measured by an immunoradiometric assay with monoclonal antibodies to two different epitopes of apo(a) (Pharmacia Diagnostics $A B$ ). $1 \mathrm{U} / 1$ of $a p o(a)$ is equivalent to $0.1 \mathrm{mg} / \mathrm{dl}$ of $\mathrm{Lp}(\mathrm{a})$. A standard curve was constructed for each assay and all samples were measured in duplicate. The within assay coefficient of variation was $3.8 \%$ and the minimum detection limit was $8 \mathrm{U} / 1$.

\section{STATISTICAL ANALYSIS}

The results of biochemical and lipid analysis are expressed as mean (SEM) for the three groups of patients. Mean apo(a) and triglyceride concentrations were logarithmically transformed for the purposes of statistical analysis because these data are known to be positively skewed within the population. The geometric mean with confidence intervals was calculated for the apo(a) concentrations in each of the three groups. Data for the three groups were compared by an analysis of variance and the significance of differences between groups was determined by Scheffés test. Categorical variables were compared by $\chi^{2}$ test. The association between apo(a) and coronary artery disease was measured by calculating the sample odds ratio ${ }^{24}$ for apo(a) concentrations above and below the cohort median $(206 \mathrm{U} / \mathrm{l})$. A p value $<0.05$ was regarded as statistically significant.

\section{Results}

There was no angiographically demonstrable coronary artery disease in 11 (group 1) of the 40 patients, mild to moderate disease in 12 (group 2 ), and severe disease in 17 (group 3). Table 1 shows the clinical details of these three groups of patients. They were of similar age and sex distribution and the prevalence of risk factors for coronary artery disease was comparable in the three groups. Alcohol intake was similar in the three groups and none of the patients was receiving either nicotinic acid derivatives or hormone replacement therapy, both of which may influence circulating concentrations of blood $\mathrm{Lp}(\mathrm{a}){ }^{25-27}$ Three patients in group 2 , four patients in group 3, but none of the patients in group 1 were receiving $\beta$ blockers. Nine patients complained of angina and nine had previous documentation of myocardial infarction. All these patients had angiographic evidence of coronary artery disease. Fasting blood glucose was similar in the three groups (table 2) and none of the patients was diabetic. Table 2 summarises the results of liver function tests and shows that there were no significant differences between the groups with regard to these variables.

\section{PERIPHERAL VASCULAR DISEASE}

Table 3 summarises the pattern of peripheral vascular disease in the three groups of patients. The prevalence of aneurysmal dilatation of the descending aorta and of significant atheromatous narrowing of the iliac, femoral, and popliteal vessels was similar, leading us to 
Table 2 Fasting blood glucose and liver function tests for the three groups of patients (mean (SEM))

\begin{tabular}{|c|c|c|c|c|}
\hline Variable & $\begin{array}{l}\text { Group } 1 \\
(n=11)\end{array}$ & $\begin{array}{l}\text { Group } 2 \\
(n=12)\end{array}$ & $\begin{array}{l}\text { Group } 3 \\
(n=17)\end{array}$ & $p$ \\
\hline $\begin{array}{l}\text { Blood glucose (mmol/l) } \\
\text { Aspartate transaminase (IU/l) } \\
\text { Alkaline phosphatase (IU/l) }\end{array}$ & $\begin{array}{l}4 \cdot 6(0 \cdot 1) \\
18(2) \\
93(11)\end{array}$ & $\begin{array}{l}5 \cdot 3(0 \cdot 2) \\
15(1) \\
119(15)\end{array}$ & $\begin{array}{l}5 \cdot 6(0 \cdot 7) \\
19(2) \\
130(15)\end{array}$ & $\begin{array}{l}\text { NS } \\
\text { NS } \\
\text { NS }\end{array}$ \\
\hline
\end{tabular}

conclude that the distribution of peripheral vascular disease was comparable in the three groups of patients studied.

\section{APO(a) CONCENTRATIONS}

Circulating concentrations of apo(a) were above the lower detection limit of the assay in all subjects and therefore were quantifiable in all cases. The figure and table 4 show the distribution of apo(a) in the three groups of patients.

Analysis of variance showed a significant difference in the concentrations of apo(a) between the groups $(p<0.005)$ with the apo(a) concentrations progressively increasing with the severity of coronary artery disease. Apo(a) concentrations were significantly greater in group 3 than in group 1 ( $p<0.05)$. The association between high apo(a) concentrations and coronary artery disease was reflected in a calculated sample odds ratio of $7.4(p<0.01)$ when the median apo(a) of the whole cohort $(206 \mathrm{U} / 1)$ was used as a cut off point.

\section{LIPID ANALYSIS}

There was no significant difference between the groups in terms of the concentrations of the standard lipid variables, total cholesterol and triglyceride (table 5). While concentrations of HDL cholesterol and its main protein constituent, apolipoprotein $A 1$, tended to decrease as the severity of coronary artery disease increased, the differences between the groups did not reach statistical significance. The concentrations of LDL cholesterol and its main protein constituent apolipoprotein B were comparable in the three groups of patients.

\section{Discussion}

The results of this study show an association between apo(a) concentrations and angiographically defined coronary artery disease in a group of otherwise unselected patients undergoing peripheral vascular surgery. Circulating concentrations of apo(a) are largely genetically determined but may be influenced by hepatic disease, ${ }^{18}$ hormone replacement therapy, ${ }^{27}$ and by treatment with nicotinic acid derivatives ${ }^{25}$ or neomycin. ${ }^{26}$ or both. None of these confounding factors was present among the patients in this study, implying that the concentrations of

Table 3 Distribution (n(\%)) of peripheral vascular disease in the three groups of patients

\begin{tabular}{lllcl}
\hline Disease & $\begin{array}{c}\text { Group } 1 \\
(n=11)\end{array}$ & $\begin{array}{l}\text { Group 2 } \\
(n=12)\end{array}$ & $\begin{array}{c}\text { Group 3 } \\
(n=17)\end{array}$ & $p$ \\
\hline Aortic aneurysm & $5(45)$ & $6(50)$ & $7(41)$ & NS \\
Iliac & $4(36)$ & $6(50)$ & $7(41)$ & NS \\
Femoral & $3(27)$ & $6(50)$ & $11(65)$ & NS \\
Popliteal & $3(27)$ & $0(0)$ & $5(29)$ & NS \\
\hline
\end{tabular}

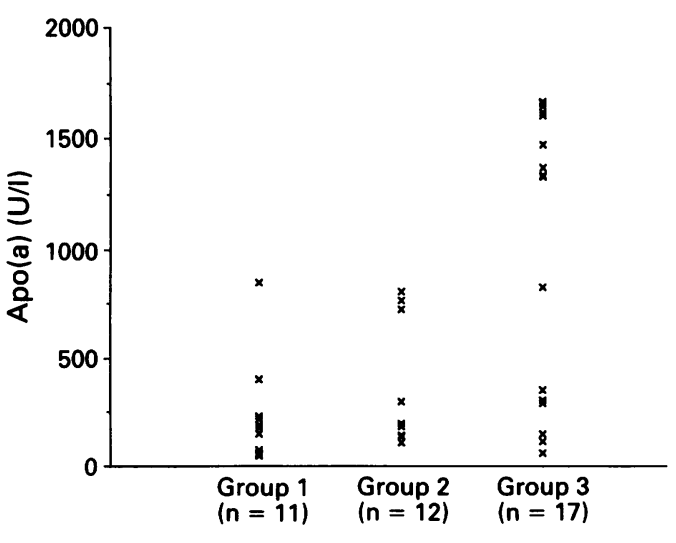

Figure Individual apo (a) concentrations in the three groups of patients.

apo(a) that were observed were predominantly $\stackrel{\circ}{3}$ a reflection of genetic predisposition. A strong? association between high apo(a) concentrations. and coronary artery disease was seen in studies $\vec{i}$ of the general population, ${ }^{12-14}$ suggesting a contributory role of apo(a) in the pathogenesis 5 of coronary atheroma. Such an association, $\vec{c}$ however, has not previously been reported in patients with advanced atherosclerosis else- $\frac{c}{0}$ where. The present results do not rule out other risk factors in the pathogenesis of coron- $\overrightarrow{0}$ ary artery disease in patients with peripheral vascular disease but they do imply that varia- $\square$ tions in the concentration of apo(a) between individuals may partly explain why only a proportion develop important coronary artery disease. Of perhaps equal interest in this study $\frac{\Phi}{\square}$ was the finding of low apo(a) in the group of $\overrightarrow{\vec{P}}$ patients without angiographically demonstra- $\frac{0}{3}$ ble coronary atheroma but with advanced peripheral vascular disease. These findings suggest that the relation between high apo (a) concen- $\vec{J}$ trations and the development of advanced $\stackrel{\overparen{D}}{\Perp}$ atheroma may vary throughout the circulation and may be less important in peripheral vessels 3 . than in coronary vessels. Epidemiologicalo studies have identified smoking ${ }^{28}$ and hypertension $^{29}$ as risk factors that may exert a greatero influence on the development of peripheral $>$ than coronary artery disease, and the results of this study corroborate the likelihood of $\bar{N}$ differences in the pathogenesis of coronary and peripheral atheroma.

The current findings may also have potential ${ }_{\omega}^{N}$ clinical implications for the management of patients with large vessel peripheral vascularo disease. The presence or absence of coincident coronary artery disease is a crucial factor in determining both the long-term prognosis ${ }^{30} \frac{0}{0}$ and the risk of surgical intervention in such patients. ${ }^{31}$ In those with severe and symp- $\frac{}{\Phi}$ tomatic peripheral vascular disease the 10 year risk of death due to coronary heart disease or cardiovascular disease is increased 10 to 150 fold $^{30}$ and the risk of vascular surgery fourfold. ${ }^{31}$ Because coronary artery disease may음 often be clinically silent ${ }^{6}$ it has been suggested that all patients with documented large vessel peripheral arterial disease should receive careful cardiovascular evaluation, ${ }^{30}$ especially before vascular surgery is undertaken. ${ }^{32}$ Simple 
Table 4 Distribution of apo (a) concentrations $(U / l)$ in the three groups of patients

\begin{tabular}{lccc}
\hline & $\begin{array}{c}\text { Group 1 } \\
(n=11)\end{array}$ & $\begin{array}{l}\text { Group 2 } \\
(n=12)\end{array}$ & $\begin{array}{c}\text { Group 3 } \\
(n=17)\end{array}$ \\
\hline Geometric mean & 112 & 214 & 537 \\
$95 \%$ CI & $(52-242)$ & $(129-355)$ & $(271-1064)$ \\
Median & 152 & 160 & 1302 \\
Range & $(19-819)$ & $(82-777)$ & $(33-1638)$ \\
\hline
\end{tabular}

and cost-effective screening methods are therefore required to identify those at greatest risk in whom modification of risk factors, intensive monitoring, or appropriate coronary intervention or both may improve prognosis. In patients undergoing vascular surgery noninvasive cardiac investigations including dipyridamole thallium scintigraphy ${ }^{32} 33$ and ambulatory electrocardiographic monitoring $^{3435}$ have been helpful, especially when interpreted in combination with clinical risk factors. ${ }^{36}$ In the present study patients with circulating concentrations of apo(a) that were greater than the cohort median had an estimated $7 \cdot 4$ fold increase in the likelihood of underlying coronary artery disease. These results suggest that the measurement of apo(a) may prove a useful additional screening tool in the assessment of patients with large vessel peripheral vascular disease and may help to identify those in whom further coronary investigation and appropriate intervention may be warranted.

The precise mechanism by which $\mathrm{Lp}(\mathrm{a})$ (and therefore apo(a)) promotes atherogenesis remains obscure, though the different anatomy and haemodynamic profile of the peripheral and coronary circulations may explain the variable effects of circulating $L p(a)$ concentrations at these sites. The close structural homology between apo(a) and plasminogen ${ }^{37} 38$ has suggested a link between lipoprotein metabolism and the clotting/fibrinolytic systems. $\mathrm{Lp}(\mathrm{a})$ competes in vitro with plasminogen for binding to fibrin, ${ }^{39} 40$ fibrinogen, ${ }^{41}$ and cell membrane binding sites ${ }^{41}{ }^{42}$ and may therefore interfere with plasminogen activation thereby promoting local thrombosis at the sites of pre-existing atheroma. Haemostatic factors ${ }^{43}$ and fibrin ${ }^{44}$ have been demonstrated within atheroma and the increase in fibrin content of growing atheromatous lesions $\mathrm{s}^{45}$ suggests that its rate of accumulation may influence the rate of plaque growth. When circulating concentrations of $\mathrm{Lp}(\mathrm{a})$ are high a reduction in endogenous fibrinolysis could enhance the deposition and incorporation of fibrin at sites of atheroma and thereby result in

Table 5 Lipid profile of the three groups of patients (mean (SEM))

\begin{tabular}{|c|c|c|c|c|}
\hline Variable & $\begin{array}{l}\text { Group 1 } \\
(n=11)\end{array}$ & $\begin{array}{l}\text { Group 2 } \\
(n=12)\end{array}$ & $\begin{array}{l}\text { Group } 3 \\
(n=17)\end{array}$ & $p$ \\
\hline $\begin{array}{l}\text { Total cholesterol } \\
(\mathrm{mmol} / \mathrm{l})\end{array}$ & $6.3(0.6)$ & $5.5(0.4)$ & $6 \cdot 2(0.4)$ & NS \\
\hline $\begin{array}{l}\text { HDL cholesterol } \\
(\mathrm{mmol} / \mathrm{l})\end{array}$ & $1.19(0 \cdot 16)$ & $1.03(0.06)$ & $0.93(0.06)$ & NS \\
\hline $\begin{array}{l}\text { LDL cholesterol } \\
(\mathrm{mmol} / \mathrm{l})\end{array}$ & $4 \cdot 0(0 \cdot 5)$ & $3.6(0.4)$ & $4 \cdot 2(0.3)$ & NS \\
\hline $\begin{array}{l}\log \mathrm{TG}(\mathrm{mmol} / \mathrm{l}) \\
\text { Apo A1 }(\mathrm{mg} / \mathrm{dl}) \\
\text { Apo B }(\mathrm{mg} / \mathrm{dl})\end{array}$ & $\begin{array}{l}0 \cdot 22(0 \cdot 09) \\
114(10) \\
110(14)\end{array}$ & $\begin{array}{l}0.25(0.06) \\
113(6) \\
110(9)\end{array}$ & $\begin{array}{l}0 \cdot 26(0 \cdot 04) \\
102(10) \\
122(8)\end{array}$ & $\begin{array}{l}\text { NS } \\
\text { NS } \\
\text { NS }\end{array}$ \\
\hline
\end{tabular}

HDL, high density lipoprotein; LDL, low density lipoprotein; TG, triglyceride. accelerated growth of atheromatous lesions. Alternatively, the importance of $\mathrm{Lp}(\mathrm{a})$ may relate specifically to atherogenesis rather than to thrombosis. $\mathrm{Lp}(\mathrm{a})$ competes with plasminogen for binding to receptors on the surface of human monocyte-like cells. ${ }^{46}$ Since lipid-laden macrophages are the predominant cellular component of arterial fatty streaks ${ }^{47}$ enhanced macrophage uptake of $L p(a)$ may lead to its incorporation at an early stage into atheromatous lesions where it is known to be preferentially retained bound to fibrin. ${ }^{48}$

In summary, the results of this study showed an association between apo(a) concentrations and the presence of angiographically defined coronary artery disease in patients with advanced atheromatous peripheral vascular disease. The findings corroborate the link between high apo(a) concentrations and the development of coronary artery disease but also imply differences in the pathogenesis of coronary and peripheral atheroma. Patients with both coronary and peripheral vascular disease have an increased risk associated with peripheral vascular surgery and also have a poor long-term prognosis. The findings in this study of an increased prevalence of underlying coronary artery disease in patients with high concentrations of apo(a) also imply that the measurement of apo(a) may prove to be a useful additional tool in the risk factor assessment of patients with large vessel peripheral vascular disease.

We thank Dr T J Peters, Department of Medical Computing and Statistics, University of Wales College of Medicine, for his helpful statistical advice and comments. PG is a British Heart Foundation Junior Research Fellow.

1 Tomatis LA, Fierens EE, Verbrugge GP. Evaluation of surgical risk in peripheral vascular disease by coronary surgical risk in peripheral vascular disease by coronary
arteriography: a series of 100 cases. Surgery 1972;71: 429-35.

2 Reid DD, Holland WW, Humerfelt S, Rose G. A cardiovascular survey of British postal workers. Lancet 1966; 614-8.

3 Hughson WG, Mann JI, Garrod A. Intermittent claudication: prevalence and risk factors. $\mathrm{Br} M e d \mathrm{~J} 1978 ; \mathbf{i}$ 1379-81.

4 Jamieson WRE, Janusz MT, Miyagishima RT, Gerein AN Influence of ischaemic heart disease on early and late mortality after surgery for peripheral occlusive vascular disease. Circulation 1982;66 (suppl 1):92-7.

5 Hertzer NR, Beven EG, Young JR, et al. Coronary artery disease in peripheral vascular disease: a classification of 1000 coronary angiograms and results of surgical man1000 coronary angiograms and result

6 Hertzer NR. Basic data concerning associated coronary disease in peripheral vascular patients. Ann Vasc Surg 1987;1:616-20.

7 Fowkes FGR. Aetiology of peripheral atherosclerosis. $\mathrm{Br}$ Med J 1989;i:405-6.

8 Utermann G. The mysteries of lipoprotein (a). Science 1989;246:904-10.

9 Utermann G, Menzel HJ, Kraft HG, Duba HC, Kemmler HG, Seitz C. Lp(a) glycoprotein phenotypes. Inheritance and relation to $\mathrm{Lp}(\mathrm{a})$-lipoprotein concentrations in plasma. J Clin Invest 1987;80:458-65.

10 Durrington PN, Ishola M, Hunt L, Arrol S, Bhatnagar D. Apolipoproteins(a), A1 and B and parental history in men with early onset ischaemic heart disease. Lancet 1988; with early

11 Rosengren A, Wilhelmsen L, Eriksson E, Risberg B, Wedel $H$. Lipoprotein(a) and coronary heart disease: a prospecH. Lipoprotein(a) and coronary heart disease: a prospective case-control study in a general popula
middle aged men. Lancet $1990 ; \mathbf{i i}: 1248-51$.

12 Kostner GM, Avogaro P, Cazzolato G, Marth E, Bittolo G Quinci GB. Lipoprotein $\mathrm{Lp}(\mathrm{a})$ and the risk for myocardial infarction. Atherosclerosis 1981;38:51-61.

13 Armstrong VW, Cremer P, Eberle E, et al. The association between serum $\mathrm{Lp}(\mathrm{a})$ concentrations and angiographically assessed coronary atherosclerosis. Dependence on serum LDL levels. Atherosclerosis 1986;62:249-57.

14 Dahlen GH, Guyton JR, Attar M, Farmer JA, Kautz JA, Gotto AM. Association of levels of lipoprotein (a), plasma lipids, and other lipoproteins with coronary artery disease documented by angiography. Circulation 1986;74:758-65. 
15 Murai A, Miyahara T, Fujimoto N, Matsuda M, Kameyama M. $\mathrm{Lp}$ (a) lipoprotein as a risk factor for coronary heart disease and cerebral infarction. Atherosclerosis 1986; 59:199-204.

16 Jurgens G, Koltringer P. Lipoprotein(a) in ischaemic cerebrovascular disease; a new approach to the assessment of risk for stroke. Neurology 1987;37:513-5.

17 Zenker G, Koltringer P, Bone G, Niederkorn K, Pfeiffer K, Jurgens $G$. Lipoprotein(a) as a strong indicator for cerebrovascular disease. Stroke 1986;17:942-5.

18 Marth E, Cazzolato G, Bittolo Bon G, Avogaro P, Kostne GM. Serum concentrations of $L p(a)$ and other lipoprotein parameters in heavy alcohol consumers. Ann Nutr Metab 1982;26:56-62.

19 Brandt PW, Partridge JB, Wattie WJ. Coronary arteriography; method of presentation of the arteriogram report and scoring system. Clin Radiol 1977;28:361-5.

20 Allain CC, Poon LS, Chan CSG, Richmond W, Fu PC. Enzymatic determination of total serum cholesterol. Clin Enzymatic determina

21 Wahlefeld AW. Triglycerides. Determination after enzymatic hydrolysis. In: Bergmeyer HU, ed. Methods of enzymatic hydrolysis. In: Bergmeyer HU, ed. Methods of Verlag Chemie Weinheim/Academic Press, Inc. 1974 $1831-5$

22 Warnick GR, Nguyen T, Albers AA. Comparison of improved precipitation methods for quantification of highdensity lipoprotein cholesterol. Clin Chem 1985;31. 217-22.

23 Friedewald WT, Levy RI, Fredrickson DS. Estimation of the concentration of low-density lipoprotein cholesterol in plasma, without use of the preparative ultracentrifuge. Clin Chem 1972;18:499-502.

24 Emery AEH. Disease associations. In: Methodology in medical genetics. 2nd ed. Edinburgh: Churchill Livingstone, 1986:114-25.

25 Carlson LA, Hamsten A, Asplund A. Pronounced lowering of serum levels of lipoprotein(a) in hyperlipidaemic subjects treated with nicotinic acid. J Intern Med 1989, 226:271-6.

26 Gurakar A, Hoeg JM, Kostner G, Papadopoulos NM, Brewer HB. Levels of lipoprotein Lp(a) decline with neomycin and niacin treatment. Atherosclerosis 1985; 57:293-301.

27 Soma M, Fumagalli R, Paoletti R, et al. Plasma Lp(a) concentration after oestrogen and progestagen in postmenopausal women. Lancet 1991;337:612.

28 Dawber TR. The Framingham study. Cambridge, Massachusetts: Harvard University Press, 1980:186-9.

29 Schroll M, Munck O. Estimation of peripheral atherosclerotic disease by ankle blood pressure measurements in a population studyof 60 year old men and women. Chronic Dis 1981;34:261-9.

30 Criqui MH, Langer RD, Fronek A, Feigelson HS, Klauber MR, McCann TJ, Browner D. Mortality over 10 years in patients with peripheral arterial disease. $N$ Engl J Med 1992;326:381-5

31 Gersh BJ, Rihal CS, Rooke TM, Ballard DJ. Evaluation and management of patients with both peripheral vascular and coronary artery disease. J Am Coll Cardiol 1991;18 203-14.
32 Leppo J, Plaja J, Gionet M, Tumulo J, Paraskos JA, Cutler BS. Noninvasive evaluation of cardiac risk before elective vascular surgery. J Am Coll Cardiol 1987;9:269-76.

33 Boucher CA, Brewster DC, Darling RC, Okada RD, Strauss HW, Pohost GM. Determination of cardiac risk by dipyridamole-thallium imaging before peripheral vascular surgery. N Engl J Med 1985;32:389-94.

34 Raby KE, Goldman L, Creager MA, et al. Correlation between preoperative ischaemia and major cardiac events after peripheral vascular surgery. $N$ Engl J Med 1989; 321:1296-3000.

35 Mangano DT, Browner WS, Hollenberg M, et al Association of peri-operative myocardial ischaemia with cardiac morbidity and mortality in men undergoing noncardiac surgery. N Engl J Med 1990;323:1781-8.

36 Eagle KA, Coley CM, Newell JB, et al Combining clinical and thallium data optimizes preoperative assessment of cardiac risk before major vascular surgery. Ann Intern Med 1989;110:859-66.

37 Eaton DL, Fless GM, Kohr WJ, et al. Partial amino acid sequence of apolipoprotein(a) is homologous to plasminogen. Proc Natl Acad Sci USA 1987;84:3224-8.

38 McLean JW, Tomlinson JE, Kuang JW, et al. cDNA sequence of apolipoprotein(a) is homologous to plasminogen. Nature 1987;330:132-7.

39 Loscalzo J, Weinfeld $M$, Fless GM, Scanu AM. Lipoprotein(a), fibrin binding and plasminogen activation. Arteriosclerosis 1990;10:240-5.

40 Harpel PC, Gordon BR, Parker TS. Plasmin catalyzes binding of lipoprotein(a) to immobilized fibrinogen and fibrin. Proc Natl Acad Sci USA 1989;86:3847-51.

41 Hajjar KA, Gavish D, Breslow JL, Nachman RI Lipoprotein(a) modulation of endothelial cell surface fibrinolysis and its potential role in atherosclerosis. Nature 1989;339:303-5.

42 Gonzalez-Gronow M, Edelberg JM, Pizzo SV. Further characterization of the cellular plasminogen binding site: evidence that plasminogen 2 and lipoprotein(a) compete for the same site. Biochemistry 1989;28:2374-7.

43 Smith EB, Staples EM. Haemostatic factors in human aortic intima. Lancet $1981 ; \mathbf{i}: 1171-4$.

44 Haust MD, Wyllie JC, More RH. Atherogenesis and plasm constituents. I. Demonstration of fibrin in the white plaque by the fluorescent antibody technique. $A m J$ Path 1964;44:255-67.

45 Bini A, Fenoglio JR, Sobel J, Owen J, Fejgl M, Kaplan KI Immunochemical characterization of fibrinogen, fibrin and fibrin II in human thrombi and atherosclerotic lesions. Blood 1987;69:1038-45.

46 Miles LA, Fless GM, Levin EG, Scanu AM, Plow EF. A potential basis for the thrombotic risks associated with lipoprotein(a). Nature 1989;339:301-2.

47 Steinberg D, Parthasarathy S, Carew TE, Khoo JC Witztum JL. Beyond cholesterol. Modifications of low density lipoprotein that increase its atherogenicity. $N$ Engl J Med 1989;320:915-24.

48 Smith EB, Cochran S. Factors influencing the accumulation in fibrous plaques of lipid derived from low density in protein(a) (Lp(a)). Atherosclerosis 1990;84:173-81. 